\title{
3D Microscopic Imaging and Evaluation of Tubular Tissue Architecture
}

\author{
J. JANÁČEK ${ }^{1}$, M. ČAPEK ${ }^{1}$, J. MICHÁLEK ${ }^{1}$, P. KAREN $^{1}$, L. KUBÍNOVÁ ${ }^{1}$ \\ ${ }^{1}$ Department of Biomathematics, Institute of Physiology Academy of Sciences of the Czech \\ Republic, Prague, Czech Republic
}

Received October 2, 2013

Accepted October 23, 2013

\section{Summary}

3D microscopy and image analysis provide reliable measurements of length, branching, density, tortuosity and orientation of tubular structures in biological samples. We present a survey of methods for analysis of large samples by measurement of local differences in geometrical characteristics. The methods are demonstrated on the structure of the capillary bed in a rat brain.

\section{Key words}

Confocal microscopy • Capillaries • Brain • Skeletal muscle • Image analysis

\section{Corresponding author}

J. Janáček, Institute of Physiology, Academy of Sciences of the Czech Republic, Vídeňská 1083, 14220 Prague 4, Czech Republic. E-mail: janacek@biomed.cas.cz

\section{Introduction}

Various tissues consist of tubules connected in complicated networks. An example is the bloodstream formed by blood vessels and capillaries. Such networks can be modeled by networks of lines and described by quantitative characteristics such as length, density or connectivity. The characteristics influence the physiological properties of the capillary bed and provide necessary parameters for physical models of the transport processes in tissues (Krogh 1919, Ji et al. 2006).

Recent imaging techniques provide spatial data containing 3D images of the tissues. Structures formed by relatively thin and sparse tubules are suitable objects of $3 \mathrm{D}$ imaging. Thus, blood capillaries in brain
(Kubínová et al. 2013) and skeletal muscle (Čebašek et al. 2010) can be visualized and studied in 3D by confocal microscopy. New methods of staining and clearing thick sections of tissues (Chung et al. 2013) broaden the field of applications of 3D microscopic methods.

3D data enable direct analysis of the geometric properties of complex networks by image analysis techniques. We will show that the image processing techniques can also be applied to reconstruction of the networks in large regions of a tissue, combining data from adjacent sections and fields of view. By this approach we can measure the local values of the characteristics as well. Some parameters of the networks evaluated from 3D images, such as length, density and connectivity, can also be estimated by interactive stereological methods (Kubínová and Janáček 2001), obtaining comparable results (Kubínová et al. 2013) without the need of previous automated detection and reconstruction of the whole objects.

Reliable analyses require high quality primary data, i.e. contrast-rich images of uniformly and specifically labelled structures free of spatial deformations. We will demonstrate that some image imperfections can be corrected by careful data pre-processing: uneven sample illumination and light attenuation can be corrected by a method of spatial contrast equalization (Čapek et al. 2006, Michálek et al. 2011) and uniform shrinkage of thick sections can be corrected by adaptation of spatial calibration parameters (Janáček et al. 2012). The presented methods were used for the description of capillaries in a skeletal muscle and in a brain. 


\section{Imaging methods}

\section{Confocal and nonlinear scanning microscopy}

3D microscopic data are obtained from thick samples using advanced methods of optical microscopy with enhanced axial resolution. Most common approach in biology nowadays is the microscopy using the confocal effect - selection of the light originated from the in-focus part of the sample using point illumination and confocal pinhole. Microscopes using spinning discs (Petráň et al. 1968) or laser scanning illumination (Pawley 1995) are used for 3D imaging of partially transparent samples with structures stained by fluorescent dyes. Other nonlinear scanning optical techniques use nonlinear excitation of fluorophores in focus by strong illumination, e.g. two photon excitation fluorescence or second harmonic generation of signal on optically anisotropic structures (Diaspro 2010).

Success of the 3D imaging depends on careful sample preparation, including sectioning, fixation, staining and clearing. As the dye diffuses into a thick sample slowly, techniques of staining by genetically incorporating fluorescent proteins into structures of interest or perfusion of samples are the methods of choice, when available.

\section{Optical projection tomography microscopy}

Optical projection tomography (OPT) microscopy is a relatively new technique (Sharpe et al. 2002) which allows the 3D imaging of biological specimens from $2 \mathrm{~mm}$ up to $15 \mathrm{~mm}$ across. OPT enables us to acquire $3 \mathrm{D}$ images of much larger specimens than confocal microscopy. It can be applied to a non-fluorescent specimen as well as to fluorescent ones, thus allowing visualization of commonlyused stains. In tomography, the data obtained from the specimen does not provide a direct mapping to a single position in 3D space, but the total amount of light absorbed or emitted along a straight line through the specimen. The collected data act essentially like a shadow of the object. These data do not map to a specific position within the object, but when added to similar data collected from other angles, they contribute to a full description of the object. The algorithm which performs this calculation is called a back-projection algorithm.

\section{Preprocessing}

Compensation of brightness and contrast inhomogeneities in image planes and with the depth in image stacks

In images acquired by confocal laser scanning microscopy (CLSM), regions corresponding to the same concentration of fluorophores in the specimen should be mapped to the same greyscale levels. However, in practice, due to multiple distortion effects, CLSM images of even homogeneous specimen regions suffer from irregular brightness variations, e.g. darkening of image edges and lightening of the center. The effects are yet more pronounced in images of real biological specimens. A spatially varying greyscale map complicates image post-processing, e.g. in alignment of overlapping regions of two images and in $3 \mathrm{D}$ reconstructions, since measures of similarity usually assume a spatially independent greyscale map. We designed a fast correction method based on estimating a spatially variable illumination gain, and multiplying acquired CLSM images by the inverse of the estimated gain (Fig. 1). The method does not require any special calibration of reference images, since the gain estimate is extracted from the CLSM image being corrected itself. The proposed approach exploits two types of morphological filters: the median filter and the upper Lipschitz cover (Michálek et al. 2011).

Fluorescent images captured by a confocal laser scanning microscope (CLSM) from deep layers of a specimen are often darker than images from the top layers due to absorption and scattering of both excitation and fluorescent light (Fig. 2). These effects cause problems in subsequent analysis of biological objects. We designed an algorithm for brightness and contrast matching of CLSM image stacks, based on aligning distribution functions of image pairs (Čapek et al. 2006).

Both algorithms were implemented as plugins for freely distributed ImageJ software package as Plane Brightness Adjustment Plugin and Stack Contrast Adjustment Plugin, respectively, available on http://rsbweb.nih.gov/ij/plugins/.

\section{Mosaicing, montaging and registering}

Images of samples larger than the microscope field of view can be recorded by parts and reconstructed afterwards. Modern devices enable capturing a regular grid of overlapping images and straightforward reconstruction (Fig. 3).

Overlapping tiles in general position or the images from adjacent physical sections can be composed by identifying the corresponding structures (Karen et al. 2003). Elastic deformation (Čapek et al. 2009) and even discontinuities can be corrected by appropriate registration methods (Michálek and Čapek 2013). 


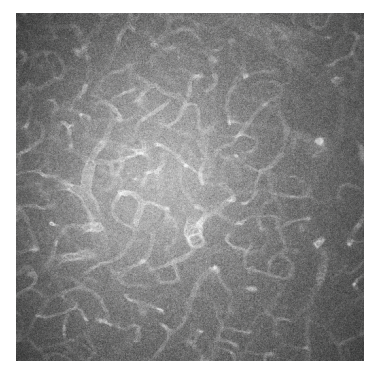

a
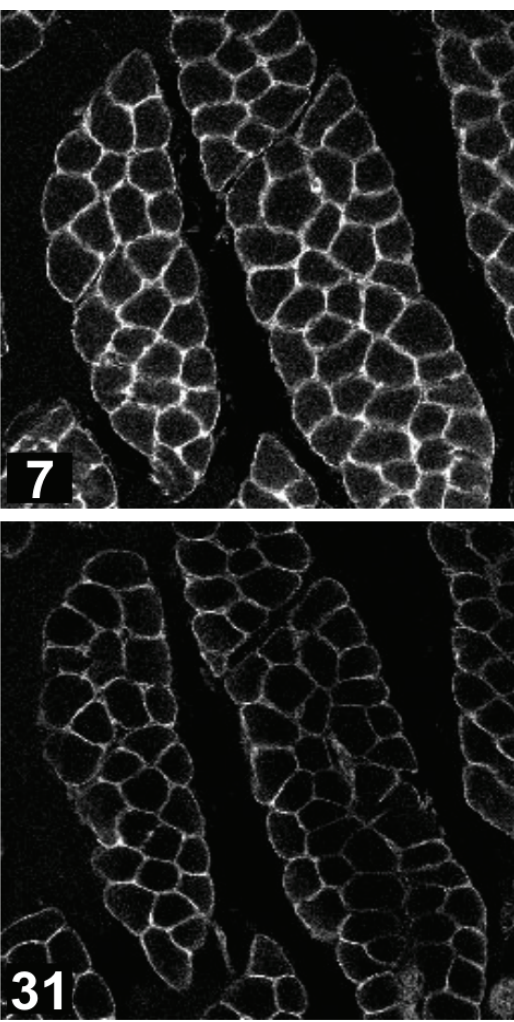

A

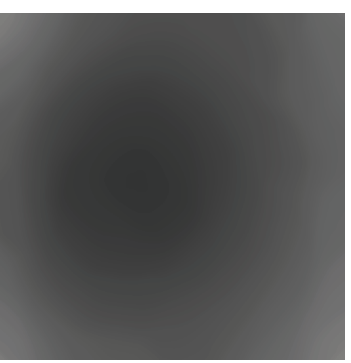

b

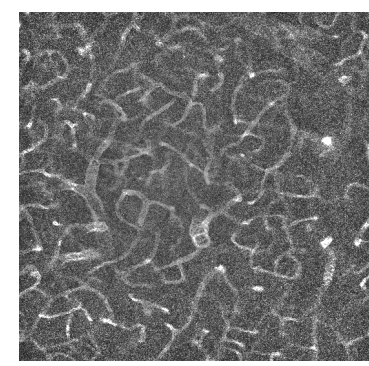

C
Fig. 1. CLSM images from a rat brain specimen: a) the original image, b) the reciprocal of the Lipschitz-cover estimated gain, c) image corrected after applying the upper Lipschitz cover morphological operator. HC PLAPO 20x water immersion objective (N.A. $=0.70$ ), the excitation wavelength of $488 \mathrm{~nm}$ and emission wavelength range from 500 to $600 \mathrm{~nm}$ were used. The size of each image is $550 \mu \mathrm{m} \times 550 \mu \mathrm{m}$.

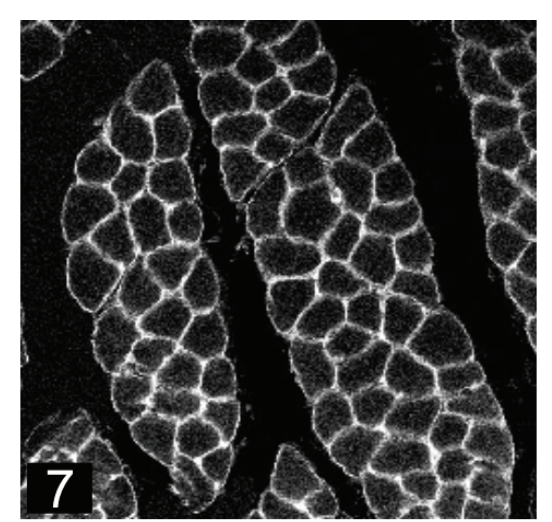

Fig. 2. A: Two images from a series of confocal optical sections of rat skeletal muscle fibres captured by a confocal microscope demonstrating the effect of the light attenuation with depth. The distance between sections in the subset is about $24 \mu \mathrm{m}$. The numbers depict numerical order of optical sections in the full series. B: Corrected subset of a series of confocal optical sections of rat skeletal muscle fibres.

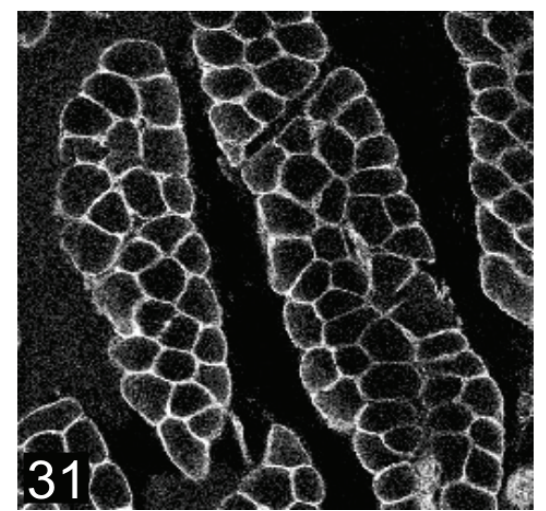

B

\section{Correction of the tissue shrinkage}

The apparent thickness of the thick tissue section in 3D confocal image may be strongly influenced by both physical deformation of the sample (Dorph-Petersen et al. 2001) and nonmatching refractive indices of objective immersion and the sample (Hell et al. 1993). The deformation occurs even in well fixed samples and must be taken into account. In homogeneous tissue, e.g. skeletal muscle, the deformation is spatially homogeneous and can be corrected simply by adapting the value of intersection axial distance (Janáček et al. 2012). The axial distance is then multiplied by a correction factor to match the apparent distance of the lower and upper surface of the thick section to the original thickness known from the microtome setting. The apparent thickness of the transversal sections is estimated as the distance between optical sections where the average intensity at the section drops to half the maximum value of section average intensity. The precision of the microtome calibration needs to be carefully checked.

\section{Segmentation}

Automatic detection of capillaries by preprocessing, thresholding and skeletonizing

The 3D confocal image with capillaries encoded by levels of gray has to be pre-processed to enable automatic segmentation by thresholding. The image has to be smoothed by a 3D Gaussian filter in order to decrease the noise level and the slowly varying background should be removed, e.g. by subtracting the 
lower Lipschitz envelope (Štencel and Janáček 2006). Binary image of capillaries obtained by thresholding can be thinned by a procedure called skeletonization using the 6-pass algorithm (Palágyi and Kuba 1998) yielding binary line skeleton. The binary image is then converted to spatial geometric graph of capillaries, composed of straight line segments (the graph edges) connected at endpoints (the graph vertices) by generating chains of line segments during automatic tracing of the thin lines in the binary image between the endpoints or branching points and connecting them to the centers of mass of the remnant thick parts. The graph is then resampled to obtain the uniform length of the line segments of moderate length, because the chains obtained by tracing procedure composed of many short segments with irregular course do not represent well the smooth course of capillaries and would yield overestimates of capillaries length. The image processing and further measurements can be accomplished by our dedicated plug-ins of Ellipse programme (ViDiTo, Slovakia). Result of this procedure is shown in Figure 3.

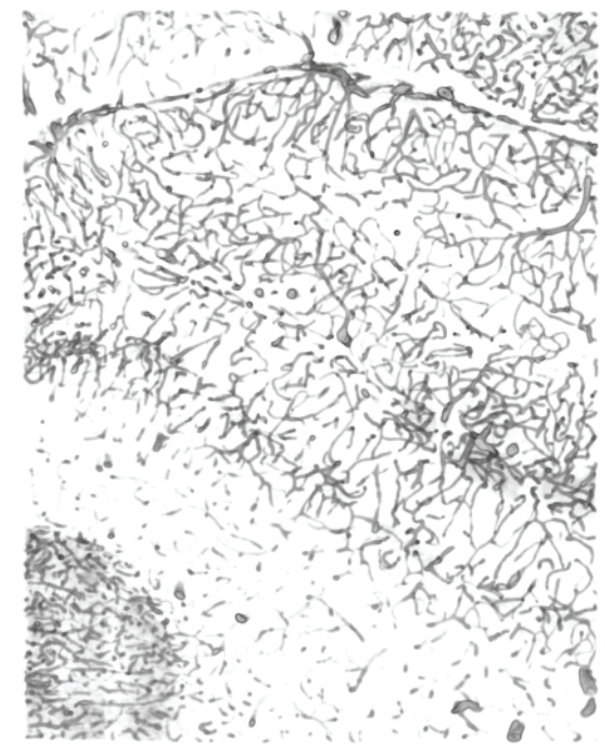

a

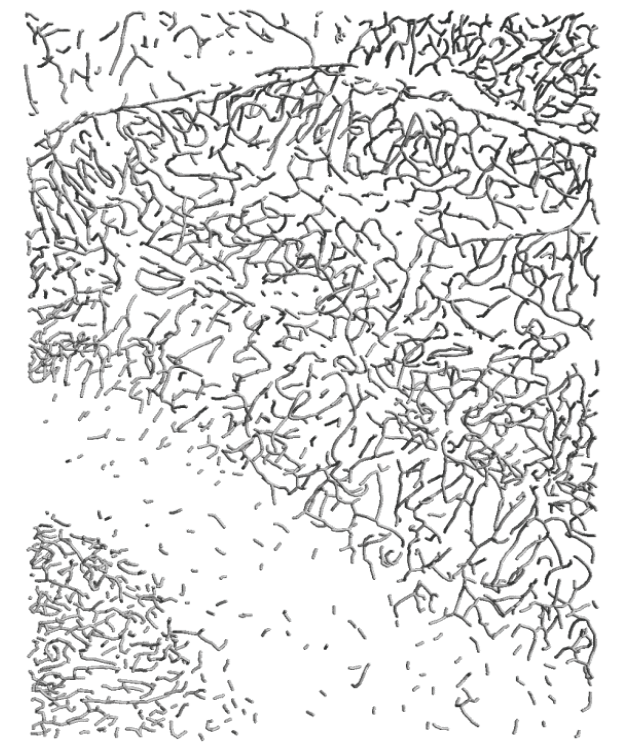

b

Fig. 3. a) Volume rendering of composite images (70 confocal stacks in 10 rows and 7 columns, $1762 \times 2519 \times 80 \mu \mathrm{m})$ and b) surface rendering of skeletonized capillaries as cylinders. Images were obtained by a confocal microscope from perfusion stained samples of rat brain.

\section{Manual tracing of capillaries}

The graphs of capillaries can be edited manually using a 3D editing program. We use a custom made program with desktop virtual reality interface for PC with Microsoft Windows. The interface consists of stereoscopic volume rendering of images with $3 \mathrm{D}$ cursor controlled by a haptic device (SensableOmni, SenseGraphics AB, Sweden) with force proportional to the gradient of the image intensity. The haptic feedback serves as a cue for depth perception and allows better placement of cursor in the capillaries. The stereoscopic rendering is accomplished either by a special graphic card with a dedicated monitor and LCD shutter glasses or by anaglyph visualization using a common display and color (RB) glasses. The program enables 3D drawing of capillaries as chains of line segments, moving individual points, connecting the chains together and deleting the vertices or chains. Alternatively other $3 \mathrm{D}$ editors such as Filament editor in the Amira program (VSG) or Tracer plug-in of Ellipse may be used for editing.

\section{Measurement of geometric characteristics}

The length of segmented structures in 3D binary images can be measured by dedicated image analysis methods based on integral geometry theorems, e.g. Crofton method (Kubínová et al. 2002, 2004). The representation of the tubular structure by $3 \mathrm{D}$ graph obtained by skeletonization is suitable for direct calculation of the length as well as of topological and orientation characteristics.

\section{Parameters describing the capillary architecture calculated from $3 D$ graphs \\ The length of capillaries is the sum of the lengths of line segments. The course of capillaries and their distribution in regard to muscle fiber orientation can be described by tortuosity, connectivity and the degree of anisotropy (capillaries orientation).}

The connectivity of the capillary bed is 
characterized by the number of capillary branchings counted manually from 3D visualization of capillaries. The number is equal to the estimate of the value $-2 \chi$, where $\chi$ is Euler-Poincaré characteristic (Gundersen et al. 1993 ) for samples of capillary network, i.e. for connected network without endpoints and with branching points, where exactly three chains connect.

Orientation of capillaries can be quantified by the degree of anisotropy computed from a matrix, called mean structural tensor (Kochová et al. 2011). The tensor is calculated in the following way: For each line segment of the traced capillaries $\langle a, b\rangle$ with endpoints $a$ and $b$ of length $L$ and direction $v=(b-a) / L$ we calculate the matrix

$$
U=\left(\begin{array}{lll}
v_{1} \cdot v_{1} & v_{1} \cdot v_{2} & v_{1} \cdot v_{3} \\
v_{2} \cdot v_{1} & v_{2} \cdot v_{2} & v_{2} \cdot v_{3} \\
v_{3} \cdot v_{1} & v_{3} \cdot v_{2} & v_{3} \cdot v_{3}
\end{array}\right)
$$

The average of all matrices (weighted by length) $T=\sum_{i} L_{i} U_{i} / \sum_{i} L_{i}$ is the mean structural tensor.

The anisotropy characteristics, fractional anisotropy (Dryden et al. 2009), is calculated from the eigenvalues $\lambda_{3} \geq \lambda_{2} \geq \lambda_{1} \geq 0, \quad \bar{\lambda}=\frac{1}{3} \sum_{i=1}^{3} \lambda_{i}$ of the mean structural tensor $T$ using the formula:

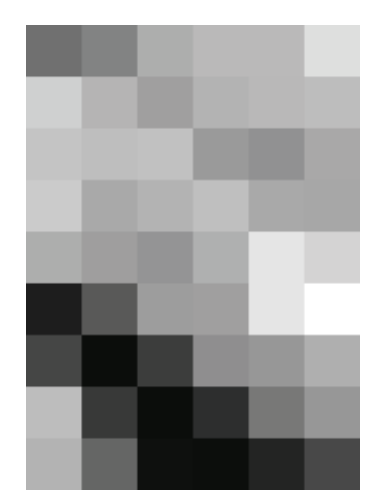

a

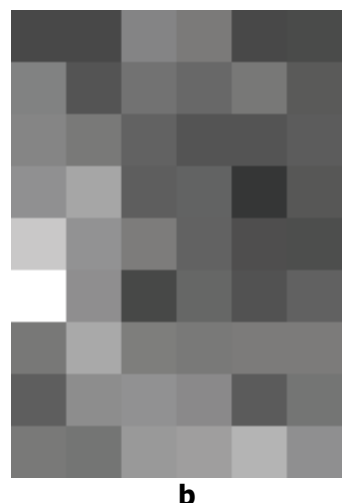

b

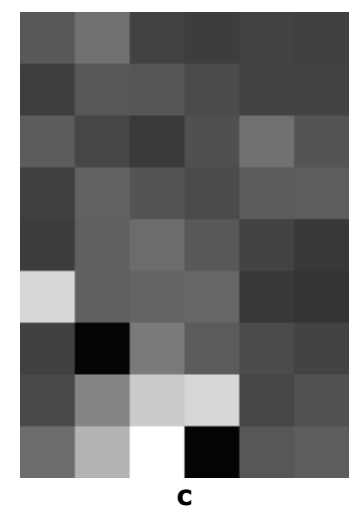

$$
F A(T)=\left(\frac{3}{2} \sum_{i=1}^{3}\left(\lambda_{i}-\bar{\lambda}\right)^{2} / \sum_{i=1}^{3} \lambda_{i}^{2}\right)^{1 / 2}
$$

The value of the characteristics is in range from 0 (i.e. isotropy - capillaries express no preferential direction) to 1 (i.e. total anisotropy - all capillaries run in the same direction).

The mean capillary length can be estimated as two thirds of the total length divided by the number of branchings. The estimator is based on the assumption that each capillary is connected to two other capillaries at both ends.

\section{Conclusions and perspectives}

Estimates of the tubuli length obtained by automated image analysis are comparable to the estimates obtained by standard interactive stereological methods (Kubínová et al. 2013). 3D image analysis estimates of capillary length were used for study of vascularization of skeletal muscle (Eržen et al. 2011). It was shown that the capillarity in rat extensor digitorum longus depends on the muscle fibre size rather than on the oxidative potential (Janáček et al. 2009).
Automated image analysis of 3D data enables measurement of many physiologically relevant characteristics at the same time and in large biological volumes. The characteristics of the orientation of the capillaries provide insight in overall bloodstream architecture in brain (Kochová et al. 2011).

Changes in 3D architecture of capillary bed may be characteristic of pathological processes and can reveal functional differences between pathological and normal tissue. For example, in terminal villi in type 1 diabetes mellitus placenta the capillary bed is thinner and more complicated (Jirkovská et al. 2012).
Fig. 4. Local measurements of the data in Figure 3. The image was split into $6 \times 9$ tiles before measurement and the value was represented by the gray level. Minimal value is represented by black. a) Length density, maximal value is $695 \mathrm{~mm}^{-2}$, b) anisotropy characteristics, maximal value is $0.74, \mathrm{c})$ average branch length, maximal value is $0.7 \mathrm{~mm}$.
Further development in imaging methods will provide new data offering further opportunities for application of image analysis methods in analysis of capillaries, ducts and neurons. New image analysis methods using the prior information about the morphology and topology of the structures under study will provide more robust estimates of quantitative and qualitative properties of tubular structures. Data on microstructure will be correlated with macroscopic measurements (e.g. by magnetic resonance imaging or optical projection tomography) and with relevant diagnoses. 


\section{Conflict of Interest}

There is no conflict of interest.

\section{Acknowledgements}

The present study was supported by the Czech Republic's public funds provided by Academy of Sciences (AV0Z50110509 and RVO:67985823), Ministry of Education, Youth and Sports (KONTAKT LH13028), and Science foundation of the Czech Republic (13-12412S).

\section{References}

CHUNG K, WALLACE J, KIM S-Y, KALYANASUNDARAM S, ANDALMAN AS, DAVIDSON TJ, MIRZABEKOV JJ, ZALOCUSKY KA, MATTIS J, DENISIN AK, PAK S, BERNSTEIN H, RAMAKRISHNAN C, GROSENICK L, GRADINARU V, DEISSEROTH K: Structural and molecular interrogation of intact biological systems. Nature 497: 332-337, 2013.

ČAPEK M, JANÁČEK J, KUBÍNOVÁ L: Methods for compensation of the light attenuation with depth of images captured by confocal microscopy. Microsc Res Tech 69: 624-635, 2006.

ČAPEK M, BRŮŽA P, JANÁČEK J, KAREN P, KUBÍNOVÁ L, VAGNEROVÁ R: Volume reconstruction of large tissue specimens from serial physical sections using confocal microscopy and correction of cutting deformations by elastic registration. Microsc Res Tech 72: 110-119, 2009.

ČEBAŠEK V, ERŽEN I, VYHNAL A, JANÁČEK J, RIBARIČ S, KUBÍNOVÁ L: The estimation error of skeletal muscle capillary supply is significantly reduced by 3D method. Microvasc Res 79: 40-46, 2010.

DIASPRO A (ed): Nanoscopy and Multidimensional Optical Fluorescence Microscopy. CRC Press, Boca Raton, London, New York, 2010.

DORPH-PETERSEN KA, NYENGAARD JR, GUNDERSEN HJG: Tissue shrinkage and unbiased stereological estimation of particle number and size. J Microsc 204: 232-246, 2001.

DRYDEN IL, KOLOYDENKO A, ZHOU D: Non-Euclidean statistics for covariance matrices, with applications to diffusion tensor imaging. Ann Appl Stat 3: 1102-1123, 2009.

ERŽEN I, JANÁČEK J, KUBÍNOVÁ L: Characterization of the capillary network in skeletal muscles from 3D data. Physiol Res 60: 1-13, 2011.

GUNDERSEN HJG, BOYCE RW, NYENGAARD JR, ODGAARD A: The Conneulor: unbiased estimation of connectivity using physical disectors under projection. Bone 14: 217-222, 1993.

HELL S, REINER G, CREMER C, STELZER EHK: Aberrations in confocal fluorescence microscopy induced by mismatches in refractive index. J Microsc 169: 391-405, 1993.

JANÁČEK J, ČEBAŠEK V, KUBÍNOVÁ L, RIBARIČ S, ERŽEN I: 3D Visualization and measurement of capillaries supplying metabolically different fiber types in the rat extensor digitorum longus muscle during denervation and reinnervation. J Histochem Cytochem 57: 437-447, 2009.

JANÁČEK J, KREFT M, ČEBAŠEK V, ERŽEN I: Correcting the axial shrinkage of skeletal muscle thick sections visualized by confocal microscopy. J Microsc 246: 107-112, 2012.

JI JW, TSOUKIAS NM, GOLDMAN D, POPEL AS: A computational model of oxygen transport in skeletal muscle for sprouting and splitting modes of angiogenesis. $J$ Theor Biol 241: 94-108, 2006.

JIRKOVSKÁ M, KUČERA T, KALÁB J, JADRNÍČEK M, NIEDOBOVÁ V, JANÁČEK J, KUBÍNOVÁ L, MORAVCOVÁ M, ŽIŽKA Z, KREJČÍ V: The branching pattern of villous capillaries and structural changes of placental terminal villi in type 1 diabetes mellitus. Placenta 33: 343-351, 2012.

KAREN P, JIRKOVSKÁ M, TOMORI Z, DEMJÉNOVÁ E, JANÁČEK J, KUBÍNOVÁ L: Three-dimensional computer reconstruction of large tissue volumes based on composing series of high-resolution confocal images by GlueMRC and LinkMRC software. Microsc Res Tech 62: 415-422, 2003.

KOCHOVÁ P, CIMRMAN R, JANÁČEK J, WITTER K, TONAR Z: How to asses, visualize and compare the anisotropy of linear structures reconstructed from optical sections - a study based on histopathological quantification of human brain microvessels. J Theor Biol 286: 67-78, 2011.

KROGH A: The number and distribution of capillaries in muscles with calculation of the oxygen pressure head necessary for supplying the tissue. $J$ Physiol 52: 409-515, 1919. 
KUBÍNOVÁ L, JANÁČEK J: Confocal microscopy and stereology: estimating volume, number, surface area and length by virtual test probes applied to three-dimensional images. Microsc Res Tech 53: 425-435, 2001.

KUBÍNOVÁ L, JANÁČEK J, KREKULE I: Stereological methods for estimating geometrical parameters of microscopic structure by three-dimensional imaging. In: Confocal and Two-Photon Microscopy: Foundations, Applications and Advances. DIASPRO A (ed), Wiley-Liss, Inc., New York, 2002, pp 299-332.

KUBÍNOVÁ L, JANÁČEK J, KAREN P, RADOCHOVÁ B, DIFATO F, KREKULE I: Confocal stereology and image analysis: methods for estimating geometrical characteristics of cells and tissues from three-dimensional confocal images. Physiol Res 53 (Suppl 1): S47-S55, 2004.

KUBÍNOVÁ L, MAO XW, JANÁČEK J: Blood capillary length estimation from three-dimensional microscopic data by image analysis and stereology. Microsc Microanal 19: 898-906, 2013.

MICHÁLEK J, ČAPEK M, KUBÍNOVÁ L: Compensation of inhomogeneous fluorescence signal distribution in 2D images acquired by confocal microscopy. Microsc Res Tech 74: 831-838, 2011.

MICHÁLEK J, ČAPEK M: A piecewise monotone subgradient algorithm for accurate $\mathrm{L}^{1}$-TV based registration of physical slices with discontinuities in microscopy. IEEE Trans Med Imag 32: 901-918, 2013.

PALÁGYI K, KUBA A: A 3D 6-subiteration thinning algorithm for extracting medial lines. Patt Rec Lett 19: 613-627, 1998.

PAWLEY J (ed): Handbook of Biological Confocal Microscopy. Plenum Press, New York, 1995.

PETRÁŇ M, HADRAVSKÝ M, EGGER MD, GALAMBOS R: Tandem-scanning reflected-light microscope. $J$ Opt Soc Am 58: 661-664, 1968.

SHARPE J, AHLGREN U, PERRY P, HILL B, ROSS A, HECKSHER-SØRENSEN J, BALDOCK R, DAVIDSON D: Optical projection tomography as a tool for 3D microscopy and gene expression studies. Science 296: 541-545, 2002.

ŠTENCEL M, JANÁČEK J: On calculation of chamfer distance and Lipschitz covers in digital images. Proceedings S4G. LECHNEROVÁ R, SAXL I, BENEŠ V (eds), Union of Czech Mathematicians and Physicists, Prague, 2006, pp 517-522. 